\title{
Review article: defining remission in ulcerative colitis
}

\author{
S. P. L. Travis ${ }^{\star}$, P. D. R. Higgins ${ }^{\dagger}$, T. Orchard ${ }^{\ddagger}$, C. J. Van Der Woude ${ }^{\S}$, R. Panaccione ${ }^{\ddagger}$, A. Bitton ${ }^{\star \star}$, C. O’Morain $^{\dagger \dagger}$,

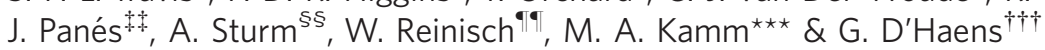

*Translational Gastroenterology Unit, John Radcliffe Hospital, Oxford, UK.

†Division of Gastroenterology and Hepatology, Department of Internal

Medicine, University of Michigan,

Ann Arbor, MI, USA.

ॠSt Mary's Hospital, London, UK.

sErasmus MC, Rotterdam, The

Netherlands

"Inflammatory Bowel Disease Clinic, University of Calgary, Calgary, $A B$, Canada.

${ }^{\star \star}$ McGill University Health Centre,

Montreal, QC, Canada.

${ }^{\dagger}$ Department of Gastroenterology,

Adelaide and Meath Hospital and

Trinity College, Dublin, Ireland.

柿Hospital Clínic de Barcelona, IDI-

BAPS CIBERehd, Barcelona, Spain.

${ }^{\S}$ Division of Gastroenterology and

Hepatology, Charité-Campus Virchow

Clinic, Universitätsmedizin Berlin,

Berlin, Germany.

"Department of Internal Medicine III, Division of Gastroenterology and

Hepatology, Medical University

Vienna, Vienna, Austria.

$\star \star \star S t$. Vincent's Hospital and University of Melbourne, Melbourne, Australia and Imperial College, London, UK.

${ }^{\dagger \dagger}$ Department of Gastroenterology,

Amsterdam Medical Center,

Amsterdam, Netherlands.

\section{Correspondence to:}

Dr S. P. L. Travis, Translational Gastroenterology Unit, John Radcliffe Hospital, Oxford, OX3 9DU, UK. E-mail: simon.travis@ndm.ox.ac.uk

\section{Publication data}

Submitted 6 February 2011

First decision 6 April 2011

Resubmitted 26 April 2011

Accepted 28 April 2011

EV Pub Online 25 May 2011

\section{SUMMARY}

\section{Background}

There is no international agreement on scoring systems used to measure disease activity in ulcerative colitis, nor is there a validated definition for disease remission.

\section{Aim}

To review the principles and components for defining remission in ulcerative colitis and propose a definition that will help improve patient outcomes.

\section{Methods}

A review of current standards of remission from the perspective of clinical trials, guidelines, clinical practice and patients was conducted by the authors. Selected literature focused on the components of a definition of remission, the utility of a definition and treatment strategies, based on current definitions.

\section{Results}

Different definitions of remission affect the assessment of outcome and make it difficult to compare trials. In the clinic, endoscopy is rarely used to confirm remission, because mucosal healing has only recently begun to be related to the duration of subsequent remission in a way that will affect clinical practice. Histopathology may be the ultimate arbiter of mucosal healing. There is no agreement on the definition of remission in current guidelines. Patient-defined remission may predict endoscopic remission, but has yet to be shown to predict duration of remission.

\section{Conclusions}

A standard based on clinical symptoms and endoscopy is proposed. Histopathology is a third dimension of remission that may have prognostic value. The definition of remission should help predict long-term outcome. The expectations of patients and their physicians need to be raised, as the goal of treatment of active ulcerative colitis should be to induce remission.

Aliment Pharmacol Ther 2011; 34: 113-124 


\section{S. P. L. Travis et al.}

\section{INTRODUCTION}

There is no international agreement on clinical, endoscopic or histopathological scoring systems in ulcerative colitis (UC). Nor is there a fully validated definition for disease remission. Definitions vary depending on whether remission is applied in a trial, regulatory, guideline, clinical or patient context. For example, the clinician may choose a particular therapeutic strategy to achieve remission, which is rarely objective and usually based on the best balance that they can achieve between symptom control and adverse events from treatment. By contrast, remission in the context of quality of life is important to the patient. Furthermore, the treatment goal or expectation of the patient may differ from that of the physician. Conversely, clinical trials generally use a definition of remission commensurate with drug registration, which is usually the objective of the study. ${ }^{1,2}$ Consequently, there are several definitions of remission:

(i) Clinical remission: used in practice, meaning cessation of rectal bleeding and normal stool frequency.

(ii) Complete remission: used in clinical trials to demonstrate safety/efficacy; normal stool frequency and no rectal bleeding as well as a normal or quiescent appearance of the mucosa at sigmoidoscopy.

(iii) Registration remission: used in trials to gain drug licence, currently used by regulatory authorities; requires cessation of rectal bleeding and a sigmoidoscopy score of 0 or 1 of the Mayo Clinic score or Ulcerative Colitis Disease Activity Index (normal appearance of the rectal mucosa or erythema only).

These definitions do not include the patient perspective, which may simply mean the ability to enjoy normal social, recreational and occupational activity without undue interference from their symptoms, or mean an even higher level of expectation, such as cure of their colitis. There is, therefore, no standard way of evaluating clinical outcomes or providing explicit recommendations for guidelines. ${ }^{3}$
It is quite possible that the absence of a standardised definition of remission has contributed to a self-perpetuating cycle of suboptimal therapy in UC (Figure 1). Long-term prognostic studies show low rates of remission $(<50 \%$ of patients), and therefore new and better (or better use of old) therapies are needed. ${ }^{1,4}$ Measurement of disease activity is critical in determining a therapy's efficacy (usually measured as the ability to induce or maintain remission). Remission rates can vary by more than two-fold depending on the definition of remission used for data analysis ${ }^{5}$ making it difficult to interpret trial data and compare results. ${ }^{1}$ This may lead to the introduction of medication which does not adequately maintain remission. Remission must therefore be clearly defined to ensure that treatment is aligned to a recognised outcome target and to standardise clinical practice. This review discusses remission as defined in clinical trials, in guidelines and clinical practice as well as the patient perspective, before discussing the key components of a standardised definition of remission.

\section{REMISSION AS DEFINED IN CLINICAL TRIALS}

No single disease activity index is used for UC, not least because there are at least seven different symptom-based activity scores, two composite scores and four patient evaluation scoring systems. ${ }^{3,}{ }^{6}$ Furthermore, the inconsistent use of names for different indices leads to considerable difficulty and confusion when comparing publications. In addition, disease measures such as the Physician's Global Assessment, patient general well-being and sigmoidoscopy are subjective evaluations that vary depending on interpretation. ${ }^{1,3}$ Some indices have never been used in a clinical trial of substantial size (e.g. Lichtiger or Modified Truelove Witts Severity Index, $\left.{ }^{7}\right)$. The lack of agreement about the best activity index for clinical trials in UC means that agreement on the assessment of remission is needed at the very least, so that the efficacy of different treatments can be compared.

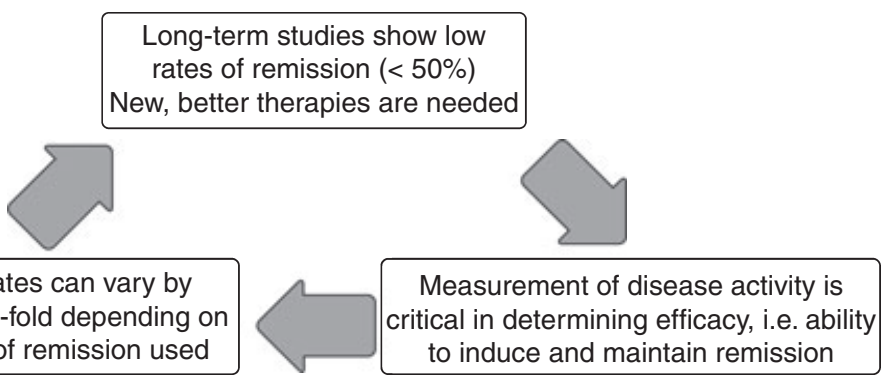

Figure 1 | Consequences of the lack of a standardised definition of remission. 
The first instrument to measure disease activity in UC was created in 1955 to quantify the clinical symptoms of UC. ${ }^{8}$ This comprised five objective variables: the number of bloody stools per day (although it may be debated whether any symptom is 'objective'); temperature; pulse; haemoglobin and erythrocyte sedimentation rate (ESR). The index was followed by a plethora of clinical, endoscopic, histological and quality of life indices and their composites (Table 1; for details see ${ }^{6}$ ). Endoscopic indices evolved from the Baron Score, initially developed for rigid proctoscopy in ambulatory patients with mild to moderate disease. ${ }^{9} \quad$ Subsequent endoscopic indices became more complex and incorporated the presence of ulcers, mucopus, granularity and light scattering in addition to bleeding and friability. ${ }^{10-12}$ Modifications were intended to improve the capture of disease activity but they invariably increased the subjectivity of the scoring system and may have undermined reproducibility. While endoscopy is likely to add stringency to the definition of remission, there is wide inter-observer variation in the assessment of mucosal appearance even by experienced investigators.

Some indices deserve more detailed consideration, because they are commonly used in clinical trials. The
Rachmilewitz index (clinical activity index, CAI) ${ }^{13}$ has been used in trials of 5-aminosalicylic acid (5ASA) ${ }^{14}$ Like many, it contains an 'investigator's global assessment' which is considered an essential clinical component but introduces subjectivity. Similarly, the endoscopic element depends on the subjective assessment of mucosal properties, including friability. The index represents combines objective (ESR, temperature and haemoglobin) and subjective findings (endoscopy, degree of abdominal pain, amount of blood in stools and physician's impression of disease). It also includes number of stools per week and extraintestinal manifestations, but paradoxically, these are neither objective nor (in the case of the latter) a reflection of disease activity. The total index score ranges from 0 to 29 points, but its main weakness is that clinical remission has come to be defined as any score less than that used to define disease activity (CAI score $>4$ ). A score of $\leq 4$ points allows a level of symptoms (which may include a stool frequency of $36-60$ /week) that cannot conceivably define remission. It fails to recognise that there is a 'grey area' in scoring systems between the threshold for defining disease activity and that used to define remission.

Table 1 | Different indices used to measure ulcerative colitis disease activity

\section{Disease}

parameter measured Disease Index

Clinical Truelove and Witts (Truelove 1955)

Powel-Tuck Index (St. Mark's Index;

Powell-Tuck 1978)

Clinical Activity Index (CAl;

Rachmilewitz 1989)

Lichtiger Index (Modified Truelove and

Witts' Severity Index; Lichtiger 1990)

Seo Index (Seo 1992)

\begin{tabular}{|c|c|c|}
\hline Endoscopic & $\begin{array}{l}\text { Truelove Witts Sigmoidoscopic } \\
\text { Assessment (Truelove 1995) } \\
\text { Baron Score (Baron 1964) } \\
\text { Endoscopic Index (El; Rachmilewitz 1989) } \\
\text { Sigmoidoscopic Index (Hanauer 1993) }\end{array}$ & $\begin{array}{l}\text { Sigmoidoscopic Inflammation Grade Score (Lemann 1995) } \\
\text { Mayo Score Flexible Proctosigmoidoscopy Assessment } \\
\text { (MSFPA; Schroeder 1987) } \\
\text { Modified Baron Score (Feagan 2005) }\end{array}$ \\
\hline $\begin{array}{l}\text { Clinical and } \\
\text { endoscopic }\end{array}$ & $\begin{array}{l}\text { Mayo Clinic Score [Mayo Clinic Disease } \\
\text { Activity Index (DAI); Schroeder 1987] }\end{array}$ & $\begin{array}{l}\text { Sutherland Index [UC Disease Activity Index (UC-DAI); } \\
\text { Sutherland 1987] }\end{array}$ \\
\hline Quality of life & $\begin{array}{l}\text { Rating form of IBD Patient Concerns } \\
\text { (Drossman 1991) } \\
\text { Inflammatory Bowel Disease Questionnaire } \\
\text { (IBDQ; Irvine 1994) }\end{array}$ & Short Form-36 (SF-36; Ware 1992) \\
\hline Histological & Riley Index (Riley 1991) & $\begin{array}{l}\text { Gebboes Index (Gebboes 2000) } \\
\text { Chicago Index (Rubin 2007) }\end{array}$ \\
\hline
\end{tabular}

For details, see D'Haens et al. ${ }^{6}$ 


\section{S. P. L. Travis et al.}

The Sutherland Index (also known as the Disease Activity Index or the UC Disease Activity Index; UCDAI) is a simplified composite score incorporating four variables: stool frequency, rectal bleeding, mucosal appearance and physician's rating of disease activity. ${ }^{15}$ By employing a four point scoring scale for each variable, the relative simplicity of the index reduces the impact of physician and patient subjectivity in disease scoring. The index has been adopted in large clinical studies. ${ }^{16}$ Of particular note, a score $<2.5$ points correlates with patient-defined remission, ${ }^{17}$ although the index has not been formally validated.

The Mayo Clinic score ${ }^{11}$ is another composite index that includes endoscopy and has been most widely used in large clinical trials of UC. ${ }^{18}$ As with the UC-DAI, the stool frequency score is not an absolute number, but relative to 'normal' for that subject, which may itself introduce variation between observers that has yet to be quantified. The FDA has recognised a relatively liberal definition of remission as a Mayo Clinic score $\leq 2$. This is less stringent than others (see below), but until the long-term predictive value for different endpoints is validated, this is unlikely to change.

The weighting of individual measures varies between scoring systems and since 'remission' is set at a particular score of the combined parameters, variation arises between the indices. Conversely, remission may be considered as the absence of disease activity, which again may be set at an arbitrary threshold below that which symptoms exist. The patient might not equate such a threshold with remission and the predictive value of different thresholds has not been examined.

\section{Impact of different definitions on the assessment of clinical trial outcomes}

In clinical trials, the definition of remission is often specific to the scoring system applied. As a result, the threshold for setting remission has a substantial impact on the remission rates in both the active and the placebo arms of clinical trials. ${ }^{19}$ Placebo remission rates vary from $<5$ to $>40 \%$ and are influenced by factors including trial duration, number of study visits, design features used to enrol patients with more active disease and intensity of endoscopic follow-up, but a stricter remission definition drives down placebo rates. ${ }^{19}$ The variety of endpoints used to define remission in clinical trials of patients with active disease is given in Table 2. The range is large and includes complete remission ( $\mathrm{DAI}=0)$, a modified UC$\mathrm{DAI} \leq 1, \mathrm{UC}-\mathrm{DAI} \leq 2, \mathrm{CAI} \leq 4$ and a Mayo Score $\leq 2$ with no individual subscore $>1{ }^{14,16,18,20,21}$

Table 2 | Indices and endpoints used in recent clinical trials with patients in active disease

\begin{tabular}{lll}
\hline Drug/study & Index/Endpoint & Endpoint definition of remission \\
\hline ASCEND II & Mayo Clinic index (DAI) & Complete remission: \\
& $\begin{array}{l}\text { Overall improvement from baseline } \\
\text { (treatment success) }\end{array}$ & A normal stool frequency and normal \\
& endoscopy findings \\
& $\begin{array}{l}\text { No rectal bleeding } \\
\text { PGA score of } 0 \text { and PFA score of } 0\end{array}$
\end{tabular}

\begin{tabular}{|c|c|c|}
\hline MEZAVANT 21 & $\begin{array}{l}\text { Modified Ulcerative Colitis Disease } \\
\text { Activity Index (UC-DAI) } \\
\text { Clinical and endoscopic remission }\end{array}$ & $\begin{array}{l}\text { Modified UC-DAI } \leq 1 \\
\text { Stool frequency - score } 0 \text { and } \\
\text { Rectal bleeding - score } 0 \text { and } \\
\text { Combined PGA score and sigmoidoscopy } \\
\text { score } \leq 1 \text { (no friability) and } \\
\leq 1 \text { point reduction from baseline in sigmoidoscopy score }\end{array}$ \\
\hline PINCE $^{16}$ & $\begin{array}{l}\text { UC-DAI } \\
\text { Clinical remission }\end{array}$ & $\begin{array}{l}\text { UC-DAI }<2 \\
\text { Sum of stool frequency and rectal bleeding and } \\
\text { mucosal appearance and PGA is } 0 \text { or } 1\end{array}$ \\
\hline SALOFALK ${ }^{14}$ & $\begin{array}{l}\text { CAI } \\
\text { Clinical remission }\end{array}$ & $\begin{array}{l}\text { CAI } \leq 4 \\
\text { Number of stools; percentage of bloody stools; } \\
\text { abdominal pain and general well-being in last } 7 \text { days; } \\
\text { temperature due to colitis; presence of EIMs; } \\
\text { laboratory findings (ESR and } \mathrm{Hb} \text { ) }\end{array}$ \\
\hline ACT $\mid / I^{18}$ & Mayo Clinic Index (DAI) & $\begin{array}{l}\text { Score } \leq 2 \text {; no individual subscore }>1 \\
\text { Sum of stool frequency; rectal bleeding; } \\
\text { mucosal appearance; PGA }\end{array}$ \\
\hline
\end{tabular}

DAI, Disease Activity Index; PFA, patients functional assessment; PGA, physician's global assessment. 
Differences in defining remission between clinical trials complicate comparisons of drug efficacy. This is because a patient in remission in trial A may not be in remission according to criteria applied in trial $\mathrm{B} .{ }^{1}$ The lack of standardisation makes interpretation of trials difficult, because important symptoms such as bleeding or increased stool frequency can be hidden in low scores. The differences in defining remission within a clinical trial can therefore have a major impact on the apparent efficacy of a drug (Table 3). ${ }^{5}, 22$ When the effect of epidermal growth factor (EGF) on UC was assessed by three different indices of disease activity (the PowellTuck, UC-DAI and a unique 'Simplified Symptom Score'), remission thresholds were set at score $\leq 4,0-1$ and 0 respectively. Remission rates varied between $33 \%$ and $83 \%$, depending on the index. ${ }^{22}$

A trial endpoint is more easily reached with a lower threshold (i.e. a higher score) for remission. This is apparent from the ACT trials (Active ulcerative Colitis Trials [ACT] I and II) of infliximab for patients with UC refractory to standard therapy. The definition of remission was a DAI $\leq 2$, with no individual subscore $>1$. $^{18}$ When this definition was applied (albeit to a population of patients without treatment-refractory disease) in a retrospective analysis of two large trials of mesalazine (mesalamine), ${ }^{20,} 23$ the remission rate for $2.4 \mathrm{~g}$ mesalazine increased from $22 \%$ (according to the original trial definition) to $50 \%{ }^{5}$ (Table 3 ).

\section{Impact of different definitions on patients}

The lack of a standardised definition of remission has considerable implications for patients. Specific symptoms that are important to patients, such as urgency, tenesmus or incontinence are often not addressed by indices.
Although most indices contain some measure of patient well-being, only the Simple Clinical Colitis Activity Index (SCCAI) incorporates urgency and incontinence. ${ }^{24}$ In registration trials, where the main aim is to obtain a drug licence, urgency and incontinence are not assessed. This means that the drug registration process overlooks the control of major symptoms that are extremely important to patients.

\section{Impact of definitions of remission on long-term disease outcomes}

It is only now becoming apparent that a stringent endpoint for remission such as defined in guidelines (clinical plus endoscopic remission ${ }^{2}$ ) is related to longer duration of remission. For example, an endoscopic score of 0 (defined as complete mucosal healing) applied to a post hoc analysis of the ACT I and II trials revealed that patients with healing at week 8 had a four-fold increased likelihood of remission at week 30 of infliximab treatment. ${ }^{25}$ This is as might be expected, but needs to be confirmed if clinical practice is to change. By way of example, patients assessed by an index that did not incorporate endoscopy were less likely to be in remission at 1 year follow-up than those whose remission was defined more stringently by endoscopic, as well as clinical criteria (Figure 2), ${ }^{26,27}$ although caution is necessary, as it compares different studies. Finessing the endoscopic mucosal friability component of the Sutherland Index to develop the more stringent 'Modified UC-DAI' has affected long-term remission rates in prospective clinical studies. Using the Modified UC-DAI, patients receiving Multi-Matrix System (MMX) mesalazine achieved and maintained remission rates $>60 \%$ at 4 months and 1 year follow-up. ${ }^{28,} 29$

Table 3 | Impact of different definitions of remission threshold on clinical trial outcomes

\begin{tabular}{|c|c|c|c|c|c|c|}
\hline \multirow{2}{*}{$\begin{array}{l}\text { Study } \\
\text { Index }\end{array}$} & \multicolumn{3}{|c|}{ ASCEND I/II 20,23} & \multicolumn{3}{|l|}{ EGF study $^{22}$} \\
\hline & \multicolumn{3}{|c|}{ Mayo/DAI } & Powell-Tuck & UC-DAI & SSS \\
\hline criteria included & \multicolumn{3}{|c|}{$\begin{array}{l}\text { Stool frequency relative to } \\
\text { normal } \\
\text { Rectal bleeding } \\
\text { Sigmoidoscopy } \\
\text { PFA } \\
\text { PGA }\end{array}$} & $\begin{array}{l}\text { Bowel frequency } \\
\text { Stool consistency } \\
\text { Abdominal pain } \\
\text { Rectal bleeding } \\
\text { EIS, temperature } \\
\text { Sigmoidoscopy }\end{array}$ & $\begin{array}{l}\text { Stool frequency } \\
\text { Rectal bleeding } \\
\text { Mucosal appearance } \\
\text { Physician's rating }\end{array}$ & $\begin{array}{l}\text { Stool consistency } \\
\text { Blood in stool } \\
\text { Nocturnal defaecation }\end{array}$ \\
\hline Remission score & 0 & $\leq 1$ & $\leq 2$ & $\leq 4$ & $0-1$ & 0 \\
\hline Remission rate & $22 \%$ & $28 \%$ & $50 \%$ & $83 \%$ & $33 \%$ & $83 \%$ \\
\hline
\end{tabular}

EGF, epidermal growth factor; DAI, disease activity index; PGA, physician's global assessment; PFA, patients functional assessment; SSS, simplified symptom score. 
(a) Pentasa PODIUM study:

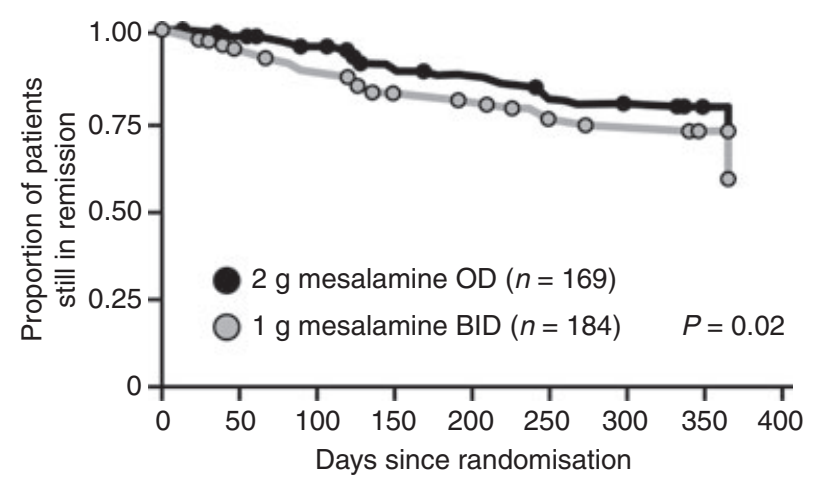

Kaplan-Meier estimated UC-DAI remission rates, where remission is defined as a UC-DAl total score $<2$

From Dignass, et al. ${ }^{26}$

(b) Mesalazine maintenance study:

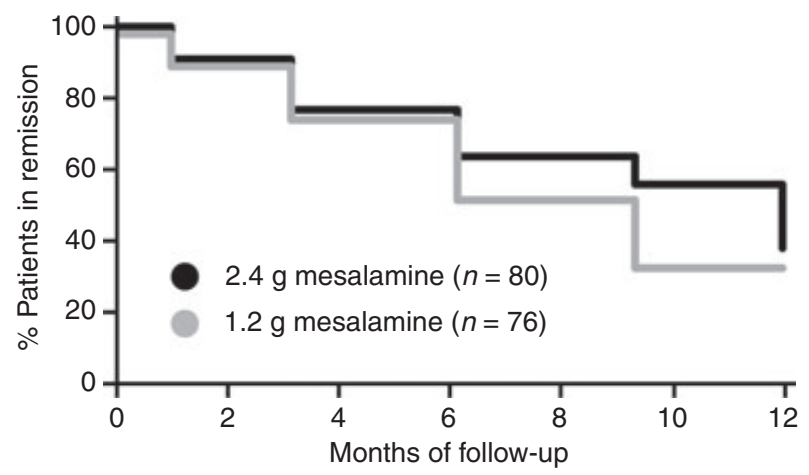

Patients (\%) in $2.4 \mathrm{~g}$ and $1.2 \mathrm{~g}$ groups in remission up to 12 months, where remission is defined according to Truelove \& Witts - NB: no endoscopic component

From Paoluzi, et al. ${ }^{27}$

Figure 2 | Apparent effect of stringency of endpoint definition on remission rates in ulcerative colitis. The comparison is between different trials.

The concept of 'deep remission' is developing in Crohn's disease, but has not yet transferred to ulcerative colitis. Nevertheless, there are data suggesting that the more criteria by which remission is defined, the better the longterm outcome. The combination of clinical, endoscopic and histological remission has been reported to be associated with a $70 \%$ likelihood of remaining in steroid-free remission over the next two and a half years (Odds Ratio for steroid-free remission $0.20,95 \%$ CI $0.08-0.47$, $P=0.002$ compared with patents without remission at the start of a cohort study of 87 patients). Furthermore, histological remission was associated with a lower rate of hospitalisation (OR $0.27,95 \%$ CI $0.07-0.95, P=0.048$ ) during the median 29 month follow-up in this small cohort. ${ }^{30}$
These preliminary data need confirmation, but if histopathology can act as a surrogate marker for a lower rate of hospital admission in future years, then this may be a relevant outcome to include in clinical trials.

\section{Role of non-invasive surrogate markers of mucosal} healing in clinical trials

Non-invasive surrogates of mucosal healing would help lower study costs and might increase patient participation in clinical trials. ${ }^{31}$ Neutrophil-derived proteins in faeces can act as biomarkers of endoscopic inflammation. ${ }^{32}$ Specifically, patients with active UC have higher levels of faecal lactoferrin, calprotectin or neutrophilelastase. These biomarkers appear to be able to differentiate active from inactive disease. ${ }^{32}$ Indices such as the Seo Index ${ }^{33}$ use multiple biomarkers and can identify patients meeting the 'regulatory definition' of remission (i.e. a score $<120$ identifies patients with no more than grade 1 on a modified Baron endoscopic score and the absence of visible blood). ${ }^{31}$ Although the Seo index correlates with other disease activity indices ${ }^{31,34}$ and endoscopic findings, ${ }^{35}$ as well as having some predictive value for patient outcomes, ${ }^{34,36}$ it is too complex to use in practice. Clinical trials are now using faecal biomarkers of mucosal inflammation, but outcomes are awaited, so their value remains unclear. Histopathology may yet turn out to be a more useful and accessible measure.

\section{Long-term implications of a stringent definition of remission for clinical trials}

The lack of microscopic inflammation on a mucosal biopsy effectively excludes active UC and this is an important measure for validating active disease when recruiting patients to clinical trials, as it can be assessed independently from endoscopy. Given the problems associated with inappropriate recruitment as a result of subjective over-scoring of clinical and endoscopic appearances, including histopathology in the definition of remission might ensure its presence among inclusion criteria. This is, however, complex. There are logistic constraints on the time to histological analysis, especially by a central reader, that effectively prevent it being used as an inclusion criterion, other than to exclude in retrospect those patients with inactive disease. Nevertheless, histological healing (from active inflammation to quiescent disease) is potentially a useful measure of treatment success, especially if histopathology predicts long-term remission. Were trials of maintenance therapy only to include patients in histological (as well as clinical and endoscopic) remission, however, the risk of relapse may 
then become too low for an effect of treatment to be detected. The role of histopathology appears best to be confined to confirming disease activity at trial entry and predicting the risk of relapse or long-term remission at trial completion.

Clinical trials are typically 6 to 8 weeks' duration and many have relied on clinical rather than endoscopic (mucosal healing) endpoints, which may have lead to artificially high remission rates. ${ }^{29}$ Given the impact of a stringent definition on the longer term remission rate, future trials should adopt stringent endpoints to identify new treatments that are effective in preventing relapse. The particular questions that need to be addressed by future clinical trials are whether endoscopy adds sufficient value to clinically defined remission to justify routine endoscopic confirmation of remission in practice, whether histological remission is really a surrogate marker for steroid- and hospitalisation-free remission and whether less invasive biomarkers are as reliable. This can then reasonably be expected to impact on the defined incidence of future flares, hospitalisation, colectomy and colon cancer in routine practice. ${ }^{37,38}$

\section{REMISSION AS DEFINED IN GUIDELINES}

Clinical guidelines should provide independent and practical recommendations for best clinical practice. Current guidelines offer some direction in setting a definition of remission, despite the lack of validated definitions of either remission or active disease. On the other hand, different activity indices and definitions may lead to substantial differences between guidelines for using the various classes of drugs.

\section{Definitions of remission used in current guidelines}

All guidelines discuss disease remission, but not all are explicit in their definition, which compromises their utility. The World Gastroenterology Organisation (WGO) Global Guidelines ${ }^{39}$ define remission as a UC-DAI $\leq 2$, which implies modest control of symptoms. By contrast, both the European Crohn's and Colitis Organisation (ECCO) ${ }^{2}$ and the International Organisation for the study of IBD (IOIBD) ${ }^{6}$ define it as 'complete resolution of symptoms and endoscopic mucosal healing'. Nevertheless, neither the Practice Parameters Committee of the American College of Gastroenterology (ACG) ${ }^{40}$ nor British Society of Gastroenterology (BSG) ${ }^{41}$ defines remission.

\section{Long-term implications of guideline recommendations}

The implication for clinical practice is wide variation in treatment, wide variation in outcomes and, more impor- tantly, acceptance of a low level of efficacy by physicians on behalf of their patients. A major aim of guidelines should be to raise the expectations and standard of care for both patients and physicians. Not all recommended therapies have been assessed by precise definitions of remission, because clinical trials typically fail to adopt a definition of remission supported by guidelines. Furthermore, guidelines quickly become outdated. Current guidelines were generally compiled before clinical studies on active UC used stringent definitions of remission that were associated with long-term maintenance of remission. $^{26,28}$ Guidelines may therefore recommend suboptimal treatment, unless reviewed frequently. On the other hand, guidelines should be based on robust evidence to avoid frequent change, as this is otherwise unlikely to be adopted in clinical practice. There are no figures on how rapidly guidelines change practice, but it seems likely that guidelines currently change more rapidly than the community is able to follow.

\section{REMISSION IN CLINICAL PRACTICE}

Assumptions about standardised clinical care may be based on guidelines, but in practice, the standard question to the patient is: 'are you feeling better?' When the answer is 'yes', this alone can be considered 'success' by the physician and the treatment will continue. Too often no routine measurements are undertaken to translate 'feeling better' into a quantifiable disease parameter or objective definition of 'remission'. Consequently, clinical treatment 'success' may be a long way from disease 'remission'. Remission as an endpoint in UC requires prospective validation and should display a strong negative predictive value for the future occurrence of clinical flares, hospitalisation, use of steroids, complications such as dysplasia, or colectomy. Remission of symptoms defined entirely on clinical criteria may not be sufficient to prevent relapse, because treating symptoms alone is not enough to achieve optimal long-term outcomes. ${ }^{42,} 43$

\section{Role of endoscopy}

Clinical practice is not least influenced by the (un)acceptability of sigmoidoscopy to the patient, but this is partly due to the lack of systematic study. Patients in clinical remission may have persistent mucosal inflammation, which are associated with a higher risk of relapse. Mucosal healing assessed by the macroscopic appearance of the mucosa at endoscopy appears to predict long-term remission, ${ }^{38,} 42,44,45$ although this has yet to be quantified in a way that is meaningful to patients or clinicians. ${ }^{46}$ Mucosal healing may also reduce the risk 


\section{S. P. L. Travis et al.}

of dysplasia or cancer, predict lower rates of hospitalisation and surgery or improve quality of life, ${ }^{47}$ which are all outcomes that matter to patients. In a populationbased study in Norway, patients with endoscopy-assessed mucosal healing of UC after 1 year of treatment still had a lower risk of colectomy 7 years later. ${ }^{43}$ Considerable variation exists in European endoscopy clinical practice. ${ }^{48}$ Nevertheless, endoscopy may not reveal mucosal damage even when microscopic inflammation exists and it has been reported that endoscopy contributes little additional information to scoring clinical activity, ${ }^{30}$ which further questions the value of endoscopy in clinical practice. Long-term outcomes on the contribution that endoscopy makes to defining remission still need to be investigated.

\section{Role of histopathology}

Microscopic (histological) healing may be a better predictor than the macroscopic appearance (or clinical criteria) of time to relapse. Histological assessment revealed that indicators of acute mucosal inflammation, including crypt abscesses, mucin depletion or an acute inflammatory cell infiltrate were associated with a two- to threefold increase in the risk of UC relapse during 12 months' follow-up. ${ }^{49}$ The presence of basal plasmacytosis (i.e. dense infiltration of plasma cells in the lower third of the mucosa) in patients with quiescent UC has also been associated with a 4.5 fold increased risk of relapse. ${ }^{50}$ Using a novel six-point histological scoring system, Rubin et al. ${ }^{51}$ reported that an increased level of histological inflammation can predict both colectomy and hospitalisation in patients with UC, where a one-point increment in histological inflammation grade raised the risk of hospitalisation and surgery by $52 \%$ and $90 \%$, respectively. ${ }^{51}$ A prospective study has shown only modest agreement between clinical, endoscopic and histological measures of remission with complete agreement in just 58\% of 91 patients (kappa 0.44) and $89 \%$ agreement between endoscopy and histopathology, although a third (36\%) of those with histological remission had clinical symptoms of activity. ${ }^{52}$ Long-term (median 29 months, range 5-35) follow-up of this cohort appears to confirm the predictive value of histopathology as a measure of remission. ${ }^{30}$

\section{Role of surrogate markers of mucosal healing in clinical practice}

A high faecal calprotectin in UC has a strong negative predictive value for remission at 6 weeks and 3 months, ${ }^{53}$ but it has yet to be shown that augmenting treatment based on the results alters outcome. In a pro- spective study of patients with UC who had been in clinical remission for 6 months, the probability of relapse was $<10 \%$ over the next 12 months in those with a basal faecal calprotectin $<150 \mu \mathrm{g} / \mathrm{g} .{ }^{53}$ Similarly, follow-up of patients with UC in clinical remission revealed significantly higher basal faecal calprotectin levels in those who relapsed compared with those who remained in remission, while ESR and C-reactive protein failed to predict disease activity. ${ }^{54}$ Even if thresholds of faecal calprotectin have limited predictive value for groups of patients, faecal calprotectin is increasingly popular because it is noninvasive and individual patients can serve as their own control. The use of surrogate markers for periodic monitoring of inflammation (like a haemoglobin A1c for diabetes applied to IBD) could be quite valuable as a sensitive, non-invasive screening tool to identify asymptomatic patients who could benefit from endoscopy, if proven prospectively to have a high sensitivity for subclinical disease. Escalating treatment of patients with a rising calprotectin to prevent clinical relapse is appealing and might improve quality of life, but this is unproven and a long way from current practice.

\section{REMISSION FROM A PATIENT PERSPECTIVE: MEETING PATIENT EXPECTATIONS AND SUPPORTING ADHERENCE}

A patient's expectations of treatment and remission may differ considerably from those of the physician. Patients often have difficulty in communicating symptoms, leading physicians incorrectly to assume that no complaints equates to no symptoms. Part of the problem is that patients focus on different symptoms from their physicians. While the physician may implement a therapeutic strategy with endoscopic improvement as the goal, factors important to patients with UC concern the present or immediate future, especially the speed of symptom relief with few side effects. ${ }^{55}$ Once these acute issues are addressed, the patient focus switches to the long-term (long lasting remission of symptoms), so that they can conduct their lives without the fear of a sudden relapse. $^{55}$

Many indices contain items which patients do not recognise as being troublesome. ${ }^{56,57}$ Stool mucus, weight loss and anxiety were among 14 novel items mentioned by patients, but overlooked in indices, while tachycardia, eye symptoms and skin manifestations were incorporated, but of little concern to most patients. ${ }^{57}$ The UC: NORMAL internet survey in the US was designed to understand how patients perceive the impact of UC, relative to the perception of gastroenterologists. ${ }^{46}$ Patients 
reported, on average, eight (self-defined) flares per year, almost three times the number recognised by physicians; furthermore, only $42 \%$ of patients believed that being in remission could mean living without symptoms. This is remarkable, because most gastroenterologists regard 'remission' as being synonymous with 'no symptoms'. Gastroenterologists underestimated the impact of the disease on patients leading a normal life, but both groups recognised the difficulties in taking daily medication. Thus, the physician's belief that $41 \%$ of their patients were not adherent to their therapy was substantiated by the finding that $46 \%$ of patients admitted to non-adherence over the previous week. The results indicate that standard care is suboptimal in many patients, with patients adapting their lives to accommodate UC, rather than acting to optimise therapy. This is underappreciated by physicians, so better management strategies and education are necessary. ${ }^{46}$

\section{Remission and adherence}

Paradoxically, the patient in remission may be at particular risk of relapse, because short-term treatment success may lead to long-term failure if, in the absence of symptoms, the prospect of a patient skipping therapy increases. ${ }^{58,59}$ Unsurprisingly, the likelihood of maintaining remission is significantly lower in patients who are not compliant with therapy. Two and a half years into 5-ASA treatment, almost $90 \%$ of those who were adherent remained in remission compared with $39 \%$ of non-adherent patients. ${ }^{58}$ There are many reasons for lack of adherence in UC, including regimen complexity, male gender, new patient status, work pressures and shorter disease duration among predictors of non-adherence in UC. ${ }^{59-67}$ Predicting long-term remission cannot depend just on the clinical, endoscopic and histological definition at a point on time.

\section{KEY CONSIDERATIONS FOR A STANDARDISED DEFINITION OF REMISSION}

A definition of remission should focus on predictors of improved long-term outcomes, because this goal would satisfy patients, clinicians and regulatory bodies. It is clear that there is a need for standardisation, but the optimal parameters (clinical, endoscopic, histology and biomarkers) and specific terminology await resolution. Current standards of care could be improved with the use of a more stringent definition of remission. Pertinent questions include:

(i) Will it help predict the duration of remission?

(ii) Will it distinguish between therapies? (iii) Will it increase the uniformity of clinical trials?

(iv) Will it increase the uniformity of clinical practice?

(v) Will this translate into improved quality of life, less hospitalisation and other improved outcomes for the patient?

\section{Components of a definition of remission}

Clinical aspects. The definition of remission should include both absence of rectal bleeding and a threshold for stool frequency. It is our view that 'urgency' should be included because it is a symptom of central importance to patients, ${ }^{17,57}$ although this might be debated as it has not been systematically studied. Descriptive terms such as mild, intense or incontinence could be applied. Urgency might, however, be quantified in terms of the time in minutes that the call to stool can be deferred, although this would only be of value if it captured information that is not achieved by other items. Clinical symptoms alone do not relate to outcome and additional components are required in a definition of remission.

Endoscopy. Patients would find endoscopy unacceptable at every clinic visit. However, if it could be shown that a definition of remission including endoscopy predicted outcome in the future, then this invasive procedure might become more acceptable. Studies are necessary to validate the long-term predictive value of endoscopic remission. Endoscopy can only be justified if the result will modify patient management.

Biomarkers. The use of faecal calprotectin is currently limited, because it does not affect decision making. The negative predictive value of faecal calprotectin for the maintenance of remission requires validation in a longterm clinical trial. If calprotectin could predict the need for endoscopy, then it would become a valuable tool.

Histopathology. Histological improvement is slower to change than macroscopic appearance, but markers of acute mucosal inflammation have a reasonable negative predictive value for maintaining remission and predicting relapse. Histopathology is currently considered an impractical measure of remission in clinical practice, but if preliminary results on its value for predicting steroid-free remission and hospitalisation are confirmed, then this will be re-visited. Furthermore, the long-term association between inflammation and colorectal neoplasia means that histopathology should not lightly be disregarded.

Based on these considerations, we propose a current definition that states: 


\section{S. P. L. Travis et al.}

Remission in ulcerative colitis should mean complete cessation of rectal bleeding, urgency and increased stool frequency, best confirmed by endoscopic mucosal healing.

\section{CONCLUSIONS}

Wide variation in the definition of remission in clinical trials means that the effectiveness of different treatments is difficult to compare. As a consequence, guidelines vary and not all recommendations are anchored in a robust outcome from a clinical trial. The expectations of patients and their physicians need to be raised in clinical practice, to expect their treatment of ulcerative colitis to induce remission. A standard based on clinical symptoms and endoscopy is proposed, but whether this definition of remission translates into better long-term outcomes remains to be determined. Longitudinal studies are necessary for this to be validated, especially with regard to histopathology, in conjunction with clinical and endoscopically defined remission.

\section{ACKNOWLEDGEMENTS}

Declaration of personal interests: Alain Bitton has served as a speaker for Axcan, as a speaker, consultant and an advisory board member for Abbott Laboratories, Merc and Shire and has received research funding from Abbott Laboratories and Merck. Geert D'Haens has served as a speaker, a consultant and an advisory board member for Abbott, Centocor, Falk, Ferring, MSD, Shire and UCB. Michael Kamm has served as a speaker, consultant, or advisory board member for Abbott, Ferring, ScheringPlough and Shire. He has received research funding from Abbott. He is an employee of St Vincent's Hospital and University of Melbourne. He owns no stock and no rele- vant patents. Professor Colm O'Morain is on the International Advisory Board of Abbott, Schering Plough, and Shire Pharmaceutical companies. He has unrestricted educational grants from Abbott and Schering Plough. Remo Panaccione has served as a speaker, consultant or advisory board member for Abbott Laboratories, Ferring, Merck, Shire and Warner Chilcott. He has received research funding from Abbott Laboratories and Merck. Julian Panés has served as a speaker, consultant or advisory board member for Abbott Laboratories, Merck, Pfizer and Shire. He has received research funding from Abbott Laboratories and Schering-Plough. Walter Reinisch has served as a speaker, consultant or advisory board member for Abbott, Aesca, Astra Zeneca, Biogen, Centocor, Ferring, Elan, Essex, Genentech, MSD, Millenium, Novartis, Pharmacosmos, Schering-Plough, Shire, UCB and Vifor. Andreas Sturm has served as a speaker, consultant, or advisory board member for Falk, Shire, Ferring, Abbott Laboratories, Merck and Vifor. He has received research funding from Abbott Laboratories and Fresenius. Simon Travis has served as a speaker, consultant or advisory board member for Abbott Laboratories, Asahi, Falk, Ferring, Genentech, Glenmark, Merck, Novartis, Schering-Plough, Shire, Tillotts, UCB Pharma, Vertex, Vifor and Warner Chilcott. He has received research funding from Abbott Laboratories, Asahi, Merck. Novartis, Schering-Plough, SigmoidPharma, Vifor and Warner Chilcott. He owns no stock or relevant patents. C. Janneke van der Woude has served as a speaker, consultant, or advisory board member for Abbott Laboratories, Ferring, Merck and Shire. She has received research funding from Abbott Laboratories and Merck. Declaration of funding interests: None.

\section{REFERENCES}

1. Travis SPL, Dinesen L. Remission in trials of ulcerative colitis - what does it mean? Pract Gastroenterol 2006; 30: 17-20.

2. Stange EF, Travis SPL, Vermeire S, et al. European evidence-based Consensus on the diagnosis and management of ulcerative colitis: definitions and diagnosis. J Crohn's Colitis 2008; 2: 1-23.

3. Cooney RM, Warren BF, Altman DG, Abreu MT, Travis SP. Outcome measurement in clinical trials for ulcerative colitis: towards standardisation. Trials 2007; 8: 17-22.
4. Katz S. "Mind the Gap": an unmet need for new therapy in IBD. J Clin Gastroenterol 2007; 41: 799-809.

5. Katz S, Higgins P, Eusebio R, Yacyshyn B. Different definitions of remission for ulcerative colitis result in large variations of clinical outcome scores. Gastroenterology 2006; 130(Suppl. 2): A-482.

6. D'Haens G, Sandborn WJ, Feagan BG, et al. A review of activity indices and efficacy end points for clinical trials of medical therapy in adults with ulcerative colitis. Gastroenterology 2007; 132: 763-86.

7. Lichtiger S, Present DH, Kornbluth A, et al. Cyclosporine in severe ulcerative colitis refractory to steroid therapy. $N$ Engl J Med 1994; 330: 1841-5.

8. Truelove SC, Witts LJ. Cortisone in ulcerative colitis. Final report on a therapeutic trial. BMJ 1955; 2: 1041-8.

9. Baron JH, Connell AM, Lennard-Jones JE. Variation between observers in describing mucosal appearances in proctocolitis. BMJ 1964; 1: 89-92.

10. Powell-Tuck J, Day DW, Buckell NA, Wadsworth J, Lennard-Jones JE. Correlations between defined sigmoidoscopic appearances and other measures of disease activity in ulcerative colitis. Dig Dis Sci 1982; 27: 533-7. 
11. Schroeder KW, Tremaine WJ, Ilstrup DM. Coated oral 5-aminosalicylic acid therapy for mildly to moderately active ulcerative colitis. A randomized study. $N$ Engl J Med 1987; 317: 1625-9.

12. Rutegard I, Ahsgren L, Stenling R, Nilsson T. A simple index for assessment of disease activity in patients with ulcerative colitis. Hepatogastroenterology 1990; 37(Suppl. 2): 110-2.

13. Rachmilewitz D. Coated mesalazine (5-aminosalicylic acid) versus sulphasalazine in the treatment of active ulcerative colitis: a randomised trial. $B M J$ 1989; 298: 82-6.

14. Kruis W, Kiudelis G, Rácz I, et al. Once daily versus three times daily mesalazine granules in active ulcerative colitis: a double-blind, double-dummy, randomised, non-inferiority trial. Gut 2009; 58: $233-40$.

15. Sutherland LR, Martin F, Greer S, et al. 5-Aminosalicylic acid enema in the treatment of distal ulcerative colitis, proctosigmoiditis, and proctitis. Gastroenterology 1987; 92: 1894-8.

16. Marteau P, Probert CS, Lindgren S, et al. Combined oral and enema treatment with Pentasa (mesalazine) is superior to oral therapy alone in patients with extensive mild/moderate active ulcerative colitis: a randomised, double blind, placebo controlled study. Gut 2005; 54: 960-5.

17. Higgins PD, Schwartz M, Mapili J, Krokos I, Leung J, Zimmermann EM. Patient defined dichotomous end points for remission and clinical improvement in ulcerative colitis. Gut 2005; 54: 782-8.

18. Rutgeerts P, Sandborn WJ, Feagan BG, et al. Infliximab for induction and maintenance therapy for ulcerative colitis. $N$ Engl J Med 2005; 353: 2462-76.

19. Su C, Lewis JD, Goldberg B, Brensinger C, Lichtenstein GR. A meta-analysis of the placebo rates of remission and response in clinical trials of active ulcerative colitis. Gastroenterology 2007; 132: 516-26.

20. Hanauer SB, Sandborn WJ, Kornbluth $\mathrm{A}$, et al. Delayed-release oral mesalamine at $4.8 \mathrm{~g} /$ day ( $800 \mathrm{mg}$ tablet) for the treatment of moderately active ulcerative colitis: the ASCEND II trial. Am J Gastroenterol 2005; 100: 2478-85.

21. Kamm MA, Sandborn WJ, Gassull M, et al. Once-daily, high-concentration MMX mesalamine in active ulcerative colitis. Gastroenterology 2007; 132: 66-75.

22. Sinha A, Nightingale J, West KP, Berlanga-Acosta J, Playford RJ. Epidermal growth factor enemas with oral mesalamine for mild-to-moderate left-sided ulcerative colitis or proctitis. $N$ Engl J Med 2003; 349: 350-7.

23. Hanauer SB, Sandborn WJ, Dallaire C, et al. Delayed-release oral mesalamine
$4.8 \mathrm{~g} /$ day (800 mg tablets) compared to $2.4 \mathrm{~g} /$ day (400 mg tablets) for the treatment of mildly to moderately active ulcerative colitis: The ASCEND I trial. Can J Gastroenterol 2007; 21: 827-34.

24. Walmsley RS, Ayres RC, Pounder RE, Allan RN. A simple clinical colitis activity index. Gut 1998; 43: 29-32.

25. Colombel JF, Rutgeerts P, Reinisch W, et al. Mucosal healing in patients with ulcerative colitis associates with a reduced colectomy risk, high incidence of symptomatic remission and corticosteroid-free state. Gut 2010; 59: A411 (Abstract P1511).

26. Dignass AU, Bokemeyer B, Adamek H, et al. Mesalamine once daily is more effective than twice daily in patients with quiescent ulcerative colitis. Clin Gastroenterol Hepatol 2009; 7: 762-9.

27. Paoluzi OA, Iacopini F, Pica R, et al. Comparison of two different daily dosages (2.4 vs. $1.2 \mathrm{~g}$ ) of oral mesalazine in maintenance of remission in ulcerative colitis patients: 1-year follow-up study. Aliment Pharmacol Ther 2005; 21: $1111-$ 9.

28. Kamm MA, Lichtenstein GR, Sandborn WJ, et al. Randomised trial of once- or twice-daily MMX mesalazine for maintenance of remission in ulcerative colitis. Gut 2008; 57: 893-902.

29. Kamm MA, Lichtenstein GR, Sandborn WJ, et al. Effect of extended MMX mesalamine therapy for acute, mild-tomoderate ulcerative colitis. Inflamm Bowel Dis 2009; 15: 1-8.

30. Burger D, Thomas SJ, Walsh AJ, et al. Depth of remission may not predict outcome of ulcerative colitis over 2 years. $J$ Crohn's Colitis 2011; 5: S4-5.

31. Higgins P, Schwartz M, Mapili J, Zimmermann EM. Is endoscopy necessary for the measurement of disease activity in ulcerative colitis. Am J Gastroenterol 2005; 100: 355-61.

32. Langhorst J, Elsenbruch S, Koelzer J, Rueffer A, Michalsen A, Dobos GJ. Noninvasive markers in the assessment of intestinal inflammation in inflammatory bowel diseases: performance of fecal lactoferrin, calprotectin, and PMN-elastase, CRP, and clinical indices. Am J Gastroenterol 2008; 103: 162-9.

33. Seo M, Okada M, Yao T, Ueki M, Arima S, Okumura M. An index of disease activity in patients with ulcerative colitis. Am J Gastroenterol 1992; 87: 971-6.

34. Seo M, Okada M, Yao T, Okabe N, Maeda K, Oh K. Evaluation of disease activity in patients with moderately active ulcerative colitis: comparisons between a new activity index and Truelove and Witts classification. Am J Gastroenterol 1995; 90: 1759-63.

35. Seo M, Okada M, Maeda K, Oh K. Correlation between endoscopic severity and the clinical activity index in ulcerative colitis. Am J Gastroenterol 1998; 93: 2124-9.

36. Seo M, Okada M, Yao T, Matake H, Maeda K. Evaluation of the clinical course of acute attacks in patients with ulcerative colitis through the use of an activity index. J Gastroenterol 2002; 37: 29-34.

37. Bewtra M, Su C, Lewis JD. Trends in hospitalization rates for inflammatory bowel disease in the United States. Clin Gastroenterol Hepatol 2007; 5: 597-601.

38. Lichtenstein GR, Rutgeerts P. The importance of mucosal healing in ulcerative colitis. Inflamm Bowel Dis 2010; 16: 338-46.

39. Bernstein CN, Fried M, Krabshuis JH, et al. World Gastroenterology Organization Practice Guidelines for the diagnosis and management of IBD in 2010. Inflamm Bowel Dis 2010; 16: 112-24.

40. Kornbluth A, Sachar DB. Ulcerative colitis practice guidelines in adults: American College of Gastroenterology, Practice Parameters Committee. Am J Gastroenterol 2010; 105: 501-23.

41. Carter MJ, Lobo AJ, Travis SPL. Guidelines for the management of inflammatory bowel disease in adults. Gut 2004; 53: v1-16.

42. Rutgeerts P, Vermeire S, Van Assche G. Mucosal healing in inflammatory bowel disease: impossible ideal or therapeutic target? Gut 2007; 56: 453-5.

43. Frøslie KF, Jahnsen J, Moum BA, Vatn $\mathrm{MH}$; IBSEN Group. Mucosal healing in inflammatory bowel disease: results from a Norwegian population-based cohort. Gastroenterology 2007; 133: 412-22.

44. Egan LJ, Everett SM, Rutgeerts P. Redefining outcomes and re-evaluating remission in inflammatory bowel disease: assessing key evidence. Biologics 2008; 2(Suppl. 1): 1-14.

45. Kane S. Endoscopic healing should be a goal for everyone with ulcerative colitis. Inflamm Bowel Dis 2008 [Epub ahead of print].

46. Rubin DT, Siegel CA, Kane SV, et al. Impact of ulcerative colitis from patients' and physicians' perspectives: results from the UC:NORMAL survey. Inflamm Bowel Dis 2009; 15: 581-8.

47. Feagan BG, Reinisch W, Rutgeerts P, et al. The effects of infliximab therapy on health-related quality of life in ulcerative colitis patients. Am J Gastrenterol 2007; 102: 794-802.

48. Lakatos L, Lakatos PL. Management of inflammatory bowel diseases in Eastern Europe. Postgrad Med J 2006; 82: 270-3.

49. Riley SA, Mani V, Goodman MJ, Dutt S, Herd ME. Microscopic activity in ulcerative colitis: what does it mean? Gut 1991; 32: $174-8$.

50. Bitton A, Peppercorn MA, Antonioli DA, et al. Clinical, biological, and histo- 


\section{S. P. L. Travis et al.}

logic parameters as predictors of relapse in ulcerative colitis. Gastroenterology 2001; 120: 13-20.

51. Rubin DT, Huo D, Hetzel JT, et al. Increased degree of histological inflammation predicts colectomy and hospitalisation in patients with ulcerative colitis. Gastroenterology 2007; 132(Suppl. 1): A19 (Abstract 103).

52. Thomas SJ, Walsh AJ, Von Herbay A, et al. How much agreement is there between histological, endoscopic and clinical assessments of remission in ulcerative colitis. Gut 2009; 58(Suppl. 1): A101.

53. Gisbert JP, Bermejo F, Pérez-Calle JL, et al. Fecal calprotectin and lactoferrin for the prediction of inflammatory bowel disease relapse. Inflamm Bowel Dis 2009; 15: $1190-8$.

54. Tibble JA, Sigthorsson G, Bridger S, Fagerhol MK, Bjarnason I. Surrogate markers of intestinal inflammation are predictive of relapse in patients with inflammatory bowel disease. Gastroenterology 2000; 119: 15-22.

55. Gray JR, Leung E, Scales J. Treatment of ulcerative colitis from the patient's perspective: a survey of preferences and satisfaction with therapy. Aliment Pharmacol Ther 2009; 29: 1114-20.
56. Joyce JC, Waljee AK, Khan T, et al. Identification of symptom domains in ulcerative colitis that occur frequently during flares and are responsive to changes in disease activity. Health Qual Life Outcomes 2008; 6: 69.

57. Waljee AK, Joyce JC, Wren PA, Khan TM, Higgins PD. Patient reported symptoms during an ulcerative colitis flare: a Qualitative Focus Group Study. Eur J Gastroenterol Hepatol 2009; 21: 558-64.

58. Kane S, Huo D, Aikens J, Hanauer S. Medication nonadherence and the outcomes of patients with quiescent ulcerative colitis. Am J Med 2003; 114: 39-43.

59. Kane SV. Systematic review: adherence issues in the treatment of ulcerative colitis. Aliment Pharmacol The 2006; 23: 577-85.

60. Hawthorne AB, Rubin G, Ghosh S. Review article: medication non-adherence in ulcerative colitis - strategies to improve adherence with mesalazine and other maintenance therapies. Aliment Pharmacol Ther 2008; 27: 1157-66.

61. Prantera C, Rizzi M. 5-ASA in ulcerative colitis: improving treatment compliance. World J Gastroenterol 2009; 15: 4353-5.

62. Chaudhary N, Junior J, Tukey M, Falchuk KR, Cheifetz A, Moss AC. Impact of a patient support program on mesal- amine adherence in patients with ulcerative colitis. Gastroenterology 2009; 136(S1): S1053.

63. Saini SD, Schoenfeld P, Kaulback K, Dubinsky MC. Effect of medication dosing frequency on adherence in chronic diseases. Am J Manag Care 2009; 15: e2233.

64. Cross RK, Cheevers N, Finkelstein J. Home telemanagement for patients with ulcerative colitis (UC HAT). Dig Dis Sci 2009; 54: 2463-72.

65. Kane SV, Brixner D, Rubin DT, Sewitch MJ. The challenge of compliance and persistence: focus on ulcerative colitis. $J$ Manag Care Pharm 2008; 1(Suppl. A): s2-12.

66. Higgins PD, Rubin DT, Kaulback K, Schoenfield PS, Kane SV. Systematic review: impact of non-adherence to 5aminosalicylic acid products on the frequency and cost of ulcerative colitis flares. Aliment Pharmacol Ther 2009; 29: 247-57.

67. Kripalani S, Yao X, Haynes RB. Interventions to enhance medication adherence in chronic medical conditions: a systematic review. Arch Intern Med 2007; 167: 540-50. 